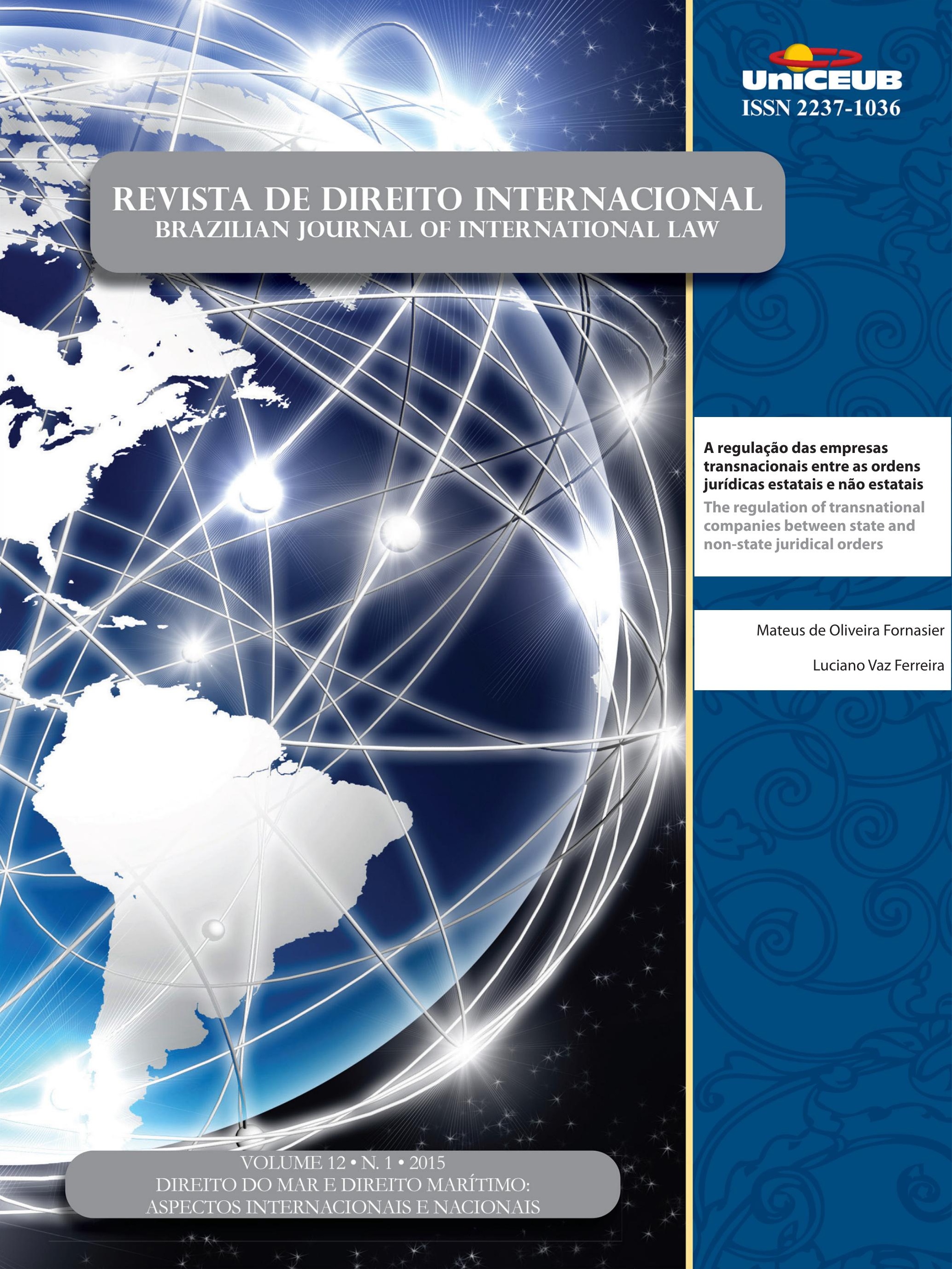




\section{Sumário}

\section{Crônicas}

CRôNICAS DA ATUALIDADE do DiREITO INTERNACIONAL ........................................................ 2

Nitish Monebhurrun (org.)

Towards a european regulation of the importation of conflict minerals?..... 2

Nitish Monebhurrun

Keeping up with the terrorists: the EU's proposed Passenger Name Records (PNR) Directive \& european security

Eshan Dauhoo

A histórica reaproximação de Cuba e EUA

Erika Braga

A contextualização da atual reivindicação da Grécia para receber indenizações por atos da Alemanha durante a Segunda Guerra Mundial . .10

Natália da Silva Gonçalves

José Eduardo Paiva Miranda de Siqueira

Crônicas da jurisprudência do Direito Internacional (CIJ/ITLOS): Decisões da Corte Internacional de Justiça e do Tribunal Internacional Sobre o Direito do Mar .14

Nitish Monebhurrun (Org.)

Corte Internacional de Justiça

Estudo da decisão da Corte Internacional de Justiça no caso Croácia v. Servia (03/02/2015) .14

Liziane Paixão Silva Oliveira e Maria Edelvacy Marinho

Questões relacionadas com a apreensão e detenção de certos documentos e dados: (Timor Leste c. Austrália) - O reconhecimento do retorno de uma relação amigável entre Timor-Leste e Austrália e a nova decisão da CIJ, 6 de maio de 2015 . 20

Gleisse Ribeiro Alves

Tribunal Internacional sobre Direito do Mar

Caso da delimitação da fronteira marítima entre o Gana e a Costa do Marfim no Oceano Atlântico: medidas cautelares $(25 / 04 / 2015)$

Nitish Monebhurrun

Comentário à Opinião Consultiva 21 do Tribunal Internacional para o Direito Do Mar [02/04/2015] (Responsabilidade do Estado de Bandeira pela pesca ilícita, não declarada ou não regulamentada) ...............25

Carina Costa de Oliveira 
CRÔNICAS DO DIREITO INTERNACIONAL DOS INVESTIMENTOS

Nitish Monebhurrun (Org.)

A inclusão da responsabilidade social das empresas nos novos Acordos de Cooperação e de Facilitação dos Investimentos do Brasil: uma revolução 33

Nitish Monebhurrun

\section{O Direito do Mar Perante as JuRisdições INTERnacionais}

CoAstal States' Rights IN THE MARITIME AREAS UNDER UNCLOS .40 Tullio Treves

TACKling illegal, unregulated And unReported Fishing: THE ITLOS Advisory OpINION on Flag State Responsibility for IUU fishing AND THE PRINCiple of DUE DiligenCE ...50 Victor Alencar Mayer Feitosa Ventura

REFLEXões PROVENIENTES do DisSENSO: UMA ANÁLISE CRÍtica A RESPEITO do CASO Austrália versus Japão Perante a Corte InTERnacional de JustiçA .......................................68 Luciana Ferna ndes Coelho

Os TRATADOS INTERNACIONAIS DE DIREITO DO MAR E SEUS EFEITOS SOBRE TERCEIROS ESTADOS ..... 86 Tiago V. Zanella

\section{InStRumentos JURÍdicos PARA A GeStÃo do MAR}

OS LIMITES DOS TERMOS BEM PÚBLICO MUNDIAL, PATRIMÔNIO COMUM DA HUMANIDADE E BENS COMUNS PARA DELIMITAR AS OBRIGAÇÕES DE PRESERVAÇÃO DOS RECURSOS MARINHOS 109 Carina Costa de Oliveira e Sandrine Maljean-Dubois

Os limites do PLANEJAMENTO DA OCUPAÇÃo SUSTENTÁVEL DA ZONA COSTEIRA BRASILEIRA ... 126 Carina Costa de Oliveira e Luciana Coelho

CORRENDO PARA O MAR NO ANTROPOCENO: A COMPLEXIDADE DA GOVERNANÇA DOS OCEANOS E A ESTRATÉGIA BRASILEIRA DE GESTÃO DOS RECURSOS MARINHOS 
A comissão de limites da Plataforma continental (CLPC) E Os DESAFios Na delineaÇÃo DAS PLATAFORMAS CONTINENTAIS ESTENDIDAS................................................... 170

Alexandre Pereira da Silva

\section{A PROTEÇÃo DO MEIO AMBIENTE MARINHO}

O gRANDE JOGo do ÁrTiCo: REFLEXões COM BASE NA PERSPECTIVA DE EXPLORAÇão ECONÔMICA

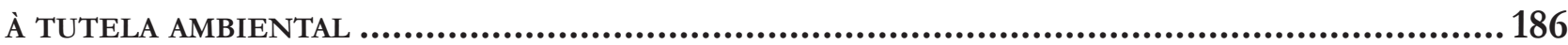

Fernando Rei e Valeria Cristina Farias

Instrumentos Públicos e Privados para a reparação do dano ambiental causado por DERRAMAMENTO DE ÓLEO NO MAR SEM ORIGEM DEFINIDA: AS MANCHAS ÓRFÃS

Renata Brockelt Giacomitti e Katya R. Isaguirre-Torres

O DIREITO INTERNACIONAL PRIVADO E A RESPONSABILIDADE CIVIL EXTRACONTRATUAL POR DANOS AMBIENTAIS CAUSADOS POR TRANSPORTES MARÍTIMOS À LUZ DO DIREITO BRASILEIRO ....... 217 Inez Lopes

A NECESSIDADE DE REPENSAR OS MECANISMOS DE RESPONSABILIDADE AMBIENTAL EM CASO DE riscos de VAZamento de PETRóleo Na Zona Econômica Exclusiva do BrasiL

Marcelo D. Varella

\section{Problemáticas do Direito Marítimo}

A FisCALIZAÇão SANitÁRIA DAS EMBARCAÇÕES EM ÁGUAS JURISDICIONAIS BRASILEIRAS: NOTAS aCERCA da (IN)efetividade da Súmula 50 da AGU

Joedson de Souza Delgado e Ana Paula Henriques da Silva

A IMO E A REPRESSÃo AO ROUBO ARMADO CONTRA NAVIOS: DA RETÓRICA INTERNACIONAL À COOPERAÇÃO REGIONAL

André Panno Beirão e Charles Pacheco Piñon

\section{O Direito do Mar diante da Pirataria}

O DIREITO INTERNACIONAL EM FACE DA PIRATARIA EM ALTO-MAR: UMA PERSPECTIVA CRÍTICA.289 Maiquel Ângelo Dezordi Wermuth e Rafaela Correa 
Pirataria marítima: A EXPERIÊnCIA Somália

Eduardo Augusto S. da C. Schneider

\section{Temas Gerais}

DRAWING THE LINE: ADDRESSING ALLEGATIONS OF UNCLEAN HANDS IN INVESTMENT ARBITRATION*

Mariano de Alba

Para Que Serve a história do Direito internacional?

George Rodrigo Bandeira Galindo

As interferências entre a Política Externa e de Segurança Comum Europeia (Pesc) e O DiREITO DAS NaÇões UNIDAS

Leonardo de Camargo Subtil

Introdução Às regras de aplicaÇão da Convenção da ONU Sobre Contratos de ComPRA E VENDA INTERNACIONAL DE MERCADORIAS E O DIREITO INTERNACIONAL PRIVADO BRASI-

LEIRO 380

Paul Hugo Weberbauer e Eugênia Cristina Nilsen Ribeiro Barza

A REgulaÇÃo das EMPRESAS TRANSNACIONAIS ENTRE AS ORDENS JURÍDICAS ESTATAIS E NÃO ESTATAIS.

Mateus de Oliveira Fornasier e Luciano Vaz Ferreira

OUtLAWING HATE SPEECH IN DEMOCRATIC STATES: THE CASE AGAINST THE INHERENT LimitAtions doctrine concerning Article 10 (1) of the European Convention on Human

Rights 416

Stefan Kirchner 


\title{
A regulação das empresas transnacionais entre as ordens jurídicas estatais e não estatais*
}

\section{The regulation of transnational companies between state and non-state juridical orders}

\author{
Mateus de Oliveira Fornasier** \\ Luciano Vaz Ferreira***
}

\section{Resumo}

Este artigo objetiva analisar as possibilidades de regulação da conduta das empresas transnacionais com base em um cenário hipercomplexo e policontextural, caracterizado pela multiplicidade de formas de comunicação, de normatização e de visões/interpretações de mundo. Busca responder: sob que condições se pode afirmar que essas empresas são reguláveis por ordens jurídicas das mais diversas origens? Como hipótese, tem-se que suas condutas são reguláveis juridicamente não apenas em ordens estatais ou internacionais, mas também com base em ordens jurídicas não estatais, relacionadas a um Direito que emerge na sociedade, e que não decorre da ação estatal. Desenvolve-se este artigo em quatro partes: a) contextualização geral da questão em trono da policontexturalidade, da hipercomplexidade e do pluralismo jurídico, considerando-se ser difícil sustentar que a regulação jurídica de âmbitos complexos possa se limitar exclusivamente às normatividades de lógica estatal; b) possibilidades territoriais e extraterritoriais de regulação das condutas das empresas transnacionais, focando-se nas possibilidades estatais ainda possíveis e importantes; c) reflexões acerca de experiências já intentadas de regulação da conduta de empresas transnacionais por normas de Direito Internacional; d) apresentar programas normativos internos de conduta das empresas transnacionais, pelas mais variadas razões, como verdadeiras ordens jurídicas não estatais — dada a complexificação societal e procedimental que essas práticas assumiram no decorrer do tempo.

* Recebido em: 15/04/2015 Aprovado em: 16/06/2015

** Doutor em Direito Público pela Universidade do Vale do Rio dos Sinos (Unisinos, Brasil). Professor do Mestrado em Direitos Humanos da Universidade Regional do noroeste do Estado do Rio Grande do Sul (Unijuí, Brasil). E-mail: mateus.fornasier@unijui.edu.br.

*** Doutor em Estudos Estratégicos Internacionais pela Universidade Federal do Rio Grande do Sul (UFRGS, Brasil). Professor da Graduação em Relações Internacionais da Universidade Federal de Rio Grande (FURG, Brasil).E-mail: lvazferreira@gmail.com.
Palavras-chave: Direito Internacional. Empresas transnacionais. Autorregulação. Policontexturalidade. Pluralismo jurídico.

\section{Abstract}

This article aims to analyze possibilities of regulating the conduct of transnational companies from a hypercomplex and polycontextural scenario, characterized by the multiplicity of ways of communication, of building norms and of visions/ interpretations of the world. It seeks to answer: under what conditions it can be said that these companies are regulable by juridical systems from several different origins? As a hypothesis, it is noticed that their conducts can have a juridical regulation not only in state or 
international orders, but also from non-state juridical orders, related to a Law that emerges in society, which is not originated by State action. This article is developed into four parts:a) general context of the matter about policontexturality, hypercomplexity and legal pluralism, considering that it is difficult to sustain that juridical regulation of complex areas may be limited exclusively inside normativities that follow State logics; b) territorial and extraterritorial possibilities of regulation of conduct of transnational companies, focusing on the State possibilities that are still possible and important; c) reflections on experiences already brought of regulating conducts of transnational corporations by International Law standards; d) presentation of internal ruling program of conduct of transnational corporations, for several reasons, as being truly non-state legal systems given the societal and procedural complexity that these practices have taken over time.

Keywords: International Law. Transnational corporations. Self-regulation. Policontexturality. Legal pluralism.

\section{INTRODUÇÃo}

A emergência de empresas transnacionais (ETNs) constitui fenômeno bastante característico do século $\mathrm{XX}$, com grandes reflexos com base nas décadas finais deste, bem como do início do século XXI — sendo correlato (e, por que não afirmar, causa e consequência) da globalização. Trata-se do surgimento de grandes atores que espraiam suas ações e comunicações para além do território de um Estado nacional, repercutindo em vários locais do globo, bem como em várias áreas das comunicações e do conhecimento - Economia, Política, Mídia de Massa, Ciência, Tecnologia e Direito, entre outras.

Tratar das implicações sociojurídicas atinentes a esses atores internacionais se demonstra trabalho de bastante importância para a atualidade. Primeiramente, pode-se justificar a escolha do tema abordado pelo aumento de complexidade — inclusive jurídico-normativa - que a grande gama de fenômenos que a globalização acarreta. Dentre esses fenômenos, apresenta-se o surgimento de novos atores internacionais que ofuscam a outrora absoluta e inquestionável soberania do Estado nacional na sociedade internacional. Esses novos atores
— que podem, não exaustivamente, ser exemplificados por organizações internacionais governamentais, organizações não governamentais (incluindo movimentos sociais de alcance internacional) e empresas transnacionais $^{1}$ - possuem não apenas relevância geopolítica: seus poderes podem se espraiar até a normatividade jurídica. Empresas transnacionais, principais atores estudados por este trabalho, possuem campo de atuação para além das fronteiras territoriais estatais, sendo capazes de constituir grandes cadeias jurídicas mediante contratos com outros entes, impondo regras e princípios de conduta que não passam, necessariamente, pela chancela do Estado $\mathrm{O}$ grande poder econômico dessas organizações reafirma a sua relevância no cenário contemporâneo - estudos apontam que várias ETNs possuem o produto interno bruto (PIB) maior do que muitos países. ${ }^{2}$

Ademais, sequer a resolução de eventuais conflitos advindos dessas cadeias perpassa, compulsoriamente, pela jurisdição tradicional: Cortes e outras instâncias não estatais constituem os meios de resolução de conflitos típicos das relações advindas dessas verdadeiras ordens jurídicas surgidas de cadeias contratuais fomentadas (e criadas) pelas empresas transnacionais.

Observa-se, nesse passo, portanto, que um olhar das comunicações jurídicas para além do Estado (mas sem, erroneamente, relegar sua atividade à desimportância) pode trazer reflexões inovadoras daquilo que seja o Direito em âmbito mundial. $\mathrm{Na}$ esteira da crise da soberania, observa-se também a crise do jurídico entendido como positivo, estatal. Contudo, essa crise não deve ser entendida como derrocada ou decadência - antes, se trata de reconfiguração cuja abordagem se faz necessária.

Wilkins ${ }^{3}$ conceitua as ETNs como "qualquer empresa que possui sede em um país e opera em, pelo menos, um país estrangeiro". Essas organizações são compostas por várias empresas em rede, em conglomerados cujo campo de comunicação (e de produção de sentido)

1 PECEQUILO, Cristina Soreanu. Introdução às relações internacionais. Petrópolis: Vozes, 2012. p. 67-83.

2 ANDERSON, Sarah; CAVANAGH, John. Top 200: the rise of corporate global power. Washington, 2000. Disponível em: <www. corpwatch.org/downloads/top200.pdf>. Acesso em: 22 jan. 2013. p. 3.

3 WILKINS, Mira. European and north american multinationals. 1870-1914: comparions and contrasts. In: JONES, Geoffrey (Org.). Transnational corporations: a historical perspective. London: Routledge, 1992. p. 23-62; p. 24. 
ultrapassa as fronteiras estatais, sendo significativamente fluidas, muitas vezes, para que uma regulação eficaz seja exercida pelo poder normativo de entes nacionais ou internacionais unicamente. ${ }^{4}$ As tentativas de regulação da conduta das corporações transnacionais mediante normativas estatais e internacionais não têm logrado êxito, pois geralmente constituem meras recomendações ineficazes. Em virtude da pesada crítica pública, disseminada globalmente pela mídia, e da ação agressiva de movimentos de protesto e organizações não governamentais (ONGs) da sociedade civil, as ETNs têm desenvolvido seus próprios códigos de conduta corporativa de maneira aparentemente voluntária, privada e pouco precisa, a fim de que sejam estabelecidas boas relações. Imprecisamente se comprometem as ETNs, com essas normativas, a implementar condutas de acordo com padrões relacionados às áreas objeto de pressão.

Este artigo se atém à análise das possibilidades de regulação da conduta das ETNs com base em um cenário hipercomplexo e policontextural - caracterizado, assim, pela multiplicidade de formas de comunicação, de normatização e de visões/interpretações de mundo. Nessa senda, busca responder ao seguinte problema de pesquisa: sob que condições se pode afirmar que essas empresas são reguláveis por ordens jurídicas das mais diversas origens? Apresenta-se como hipótese a seguinte construção teórica: suas condutas são reguláveis juridicamente (termo considerado mais amplo em significados, preferível neste artigo à noção de disciplina ${ }^{5}$, pois esta se reportaria a contextos jurídicos passados bem delimitáveis no tempo e no espaço, mormente ligados ao caráter repressivo) ${ }^{6}$ não apenas em ordens estatais ou internacionais, mas também com base em ordens jurídicas não estatais, relacionadas a um Direito que emerge na sociedade, e que não decorre da ação estatal.

4 TEUBNER, Gunther. Autoconstitucionalização de corporações transnacionais? sobre a conexão entre os códigos de conduta corporativos (Corporate Codes of Conduct) privados e estatais. Tradução de Ivar Hartmann. Revisão de Germano Schwartz. In: SCHWARTZ, Germano (Org.). Juridicização das esferas e fragmentação do direito na sociedade contemporânea. Porto Alegre: Livraria do Advogado, 2012. p. 110. 5 Acerca da Sociedade Disciplinar e da superação da predominância do seu modelo, ver: FOUCAULT, Michel. Soberania e disciplina. In: Microfísica do poder. Org. e trad. Roberto Machado. 20. ed. São Paulo: Graal, 2004. p. 100-107; DELEUZE, Gilles. Post-scriptum sobre as sociedades de controle. In:__. Conversacõoes. Trad. Peter Pál Pelbart. São Paulo: Editora 34, 2007. p. 219-226.

6 Sobre o contexto espaço-temporal do Direito Repressivo, ver: WILKE, Helmut. Reflexivo (direito). In: ARNAUD, André-Jean (Dir.). Dicionário enciclopédico de teoria e de sociologia do direito. Rio de Janeiro: Renovar, 1999. p.678-681.
A fim de melhor trabalhar com essas questões, desenvolve-se este artigo em quatro partes. A primeira delas apresenta conjuntura geral da questão em trono da policontexturalidade e da hipercomplexidade, considerando-se que atualmente é difícil sustentar a posição de que a regulação jurídica de âmbitos complexos possa se limitar exclusivamente às normatividades de lógica estatal (Direitos nacionais e internacional, mormente), pois as possibilidades lógicas e comunicativas ultrapassam, com sua fluidez, o âmbito estatal — mas o que não vem a significar que este esteja obsoleto ou superado, relegado ao passado.

Num segundo momento, apresentam-se possibilidades territoriais e extraterritoriais de regulação das condutas das ETNs. Trata-se de aspecto importante para a consecução deste trabalho, principalmente para se demonstrar que, apesar de não mais ser a única forma de normatização de condutas na atualidade, a atuação estatal ainda se configura como importantíssima - , contudo, de modo revisto e complexificado. Apresentam-se principalmente casos envolvendo a práxis jurídica estadunidense, a qual pode dar importantes subsídios de Direito Comparado para futuros estudos e análises da prática e da teoria em outros países.

No terceiro momento do desenvolvimento deste artigo são feitas reflexões acerca de experiências já realizadas de regulação da conduta de ETNs por normas de Direito Internacional. Assim, tentativas frustradas e outras em andamento são tratadas, a fim de demonstrar que óbices práticos e teóricos essa importante via encontra na prática - exemplos esses que se reportam à doutrina jurídica internacional e às ciências (mormente sociais aplicadas) sobre esse fenômeno.

Por fim, intenta-se, num quarto e último momento, seguindo-se o raciocínio baseado na policontexturalidade, na hipercomplexidade e no chamado pluralismo jurídico, apresentam-se os programas normativos internos de conduta das ETNs, pelas mais variadas razões, como verdadeiras ordens jurídicas não estatais — dada a complexificação societal e procedimental que essas práticas assumiram no decorrer do tempo. Desta feita, programas internos de compliance, mormente decorrentes das pressões sociais exercidas sobre as ETNs dos mais variados modos, bem como outras formas de regulação de condutas desses atores são apresentadas. 


\section{Pluralismo jurídico, hipercomplexidade E POLICONTEXTURALIDADE: NOVOS FATORES A SEREM SOPESADOS NA LÓGICA JURÍDICA}

A concepção do Direito pelos seus operadores e estudiosos de forma que venham a considerar, de forma simplista e errônea, a ideia da lei (estatal) como eficiente para abranger um período de tempo futuro de longa duração, deve ser desmistificada. A noção de tempo da sociedade na pós-modernidade passa a ser instantânea, rápida, manifestada pelos meios de comunicação e pela internet, enquanto os juristas continuam no texto escrito. Nota-se, portanto, defasagem significativa entre as noções de tempo e sociedade na dogmática jurídica e aquilo que a sociedade atual experimenta; paralelismo temporal imenso, pois os juristas programam normas para durarem muito tempo, e elas não duram, às vezes, dias. ${ }^{7}$ Aliás, não raro leis são aprovadas pelo Poder Legislativo quando a matéria dos seus Projetos já se encontra totalmente transformada, na realidade, em relação ao texto (fazendo com que surjam leis "nascidas velhas").

Além do tempo, ocorre paralelismo de espaço. Assim como o tempo se torna instantâneo, o espaço se torna fluido para as comunicações velozes e deslocamentos economicamente interessantes, mas bloqueado com base em antigas justificativas de soberania quando necessário (fluxos migratórios de refugiados e pessoas economicamente desinteressantes). ${ }^{8}$ Convivem, assim, pelo menos duas lógicas territoriais: uma que pouco (ou sequer) considera as fronteiras baseadas na soberania jurídico-política - seja porque simplesmente se esvazia de sentido a noção no âmbito das comunicações e resultados, como ocorre com os fluxos de dados pela rede mundial de computadores e os danos ambientais; seja porque os Estados não são capazes de afirmar sua autoridade diante de novos entes dotados de poder (ETNs, organizações criminosas transnacionais, etc.); e aquela que, principalmente, na política e no Direito tanto se reafirma, quando possível e necessário (processamento de crimes que estejam dentro das possibilidades persecutórias dos Estados; tributação e regulação de entes e fatos que não sejam capazes de se eximir dessa lógica).

Trata-se, para além da dualidade de lógicas de tem-

7 ROCHA, Leonel Severo. Epistemologia jurídica e democracia. 2. ed. São Leopoldo: Unisinos, 2003. p. 197.

8 BAUMAN, Zygmunt. Vidas desperdiçadas. Tradução de Carlos Alberto Medeiros. Rio de Janeiro: J. Zahar, 2005. po e espaço, da multitude de formas de comunicação e de normatividade. Ocorre, no âmbito global, grande fragmentação na origem das emissões de comunicação acerca de várias matérias, em muitas lógicas diversas.

A (re)configuração do Direito com a globalização se relaciona com a expansão das possibilidades de escolha proporcionada pelo aumento da complexidade social decorrente da evolução de formas estratificadas de diferenciação social para formas funcionalmente diferenciadas. Esse aumento de complexidade torna muito mais contingentes os contextos nos quais cada subsistema funcional deve operar e decidir. Em razão da multiplicidade de centros de racionalização de sentido nesse cenário, pode ser afirmado que, no ínterim do fenômeno denominado globalização, não mais se pode atribuir aos acontecimentos sociais uma existência causal unitária; ademais, a acelerada fragmentação característica dessa época faz com que as comunicações ultrapassem as fronteiras territoriais. O Direito também é afetado por essa descrita fragmentação, de forma que a efetividade do seu funcionamento se quede dependente das suas relações para com as outras instâncias sociais. Em outras palavras, pode-se afirmar que o (sub)sistema jurídico (co)evolui com racionalidades diferentes (relacionadas a outros sistemas sociais), num cenário em que o Estado não representa mais a única esfera donde a normatividade emana. Emerge, assim, uma pluralidade de atores sociais diferenciados em papéis e culturas redunda numa pluralidade de fontes normativas e de sujeitos de direitos merecedores de proteção especial (consumidores, refugiados, hipossuficientes, etc.). ${ }^{?}$

O que se observa, assim, é um pluralismo jurídico, relacionado à multiplicidade de âmbitos comunicativos em que se produzem normatividade jurídica. Nas palavras de Wolkmer, ${ }^{10}$ o pluralismo jurídico consiste na

multiplicidade de práticas jurídicas existentes num mesmo espaço sócio-político, interagidas por conflitos e consensos, podendo ser ou não oficiais e tendo a sua razão de ser nas necessidades existenciais, materiais ou culturais.

A prova da existência da multiplicidade de ordens

9 ROCHA, Leonel Severo; ATZ, Ana Paula. Do pluralismo jurídico ao diálogo inter-sistêmico das fontes na sociedade mundial. In: PEREIRA, Agostinho Oli Koppe; HORN, Luiz Fernando Del Rio (Org.). Relações de consumo: globalização. Caxias do Sul: Educs, 2010. p. 107-132. p. 109.

10 WOLKMER, Antonio Carlos. Pluralismo jurídico: fundamentos de uma nova cultura no direito. 3. ed. São Paulo: Alfa Omega, 2001. p. 219. 
jurídicas antagônicas e sobrepostas pode ser encontrada no Direito pré-Estado-Nação, particularmente no Medievo, no qual conviviam manifestações normativas concorrentes, oficiais e não oficiais, como costumes locais, foros municipais, estatutos das corporações de ofício, ditames reais, Direito Canônico e Direito Romano. ${ }^{11}$ Com a centralização do Direito na figura do Estado moderno, o fenômeno jurídico passou a ser identificado necessariamente com os atos estatais, negando-se a juridicidade das demais manifestações.

No século XX, estudiosos da Sociologia do Direito, como Ehrlich, ${ }^{12}$ Sousa Santos ${ }^{13}$ e Wolkmer ${ }^{14}$ resgataram a ideia de que o "Direito não se confunde com o Estado" e que é possível a existência de ordens jurídicas não estatais no mundo moderno. $\mathrm{Na}$ mesma linha, Teubner, ${ }^{15}$ baseando-se nos escritos de Luhmann ${ }^{16}$ e Günther ${ }^{17}$ desenvolve a ideia de "policontexturalidade", no sentido que o "Direito é fragmentado em um pluralismo em que o Estado é apenas mais uma de suas organizações". ${ }^{18}$ Sousa Santos traz como exemplos de pluralismo jurídico contemporâneo as regras de um núcleo familiar, a lex mercatoria, o Direito indígena dos povos autóctones, o Direito paralelo das comunidades estabelecidas em "favelas" brasileiras e, principalmente para o que interessa neste trabalho, os códigos internos empresariais. ${ }^{19}$

Essa defasagem fática pode ser atribuída a uma defasagem teórica: o mundo não mais suporta, em sua grande complexidade, uma lógica única. Enquanto a ló-

11 WOLKMER, Antonio Carlos. Pluralismo jurídico: fundamentos de uma nova cultura no direito. 3. ed. São Paulo: Alfa Omega, 2001. p. 184.

12 EHRLICH, Eugen. Fundamentos da sociologia do direito. Brasília: UnB, 1986.

13 SANTOS, Boaventura de Sousa. A crítica da razãa indolente: contra o desperdício da experiência. São Paulo: Cortez, 2000.

14 WOLKMER, Antonio Carlos. Pluralismo jurídico: fundamentos de uma nova cultura no direito. 3. ed. São Paulo: Alfa Omega, 2001. 15 TEUBNER, Gunther. A bukowina global sobre a emergência de um pluralismo jurídico transnacional. Impulso, Piracicaba, v. 13, n. 33, p. 09-31, 2003.

16 LUHMANN, Niklas. Como se pueden observar estructuras latentes? In: WATZLAWICK, Pal; KRIEG, Peter. El ojo del observador: contribuciones al construtivismo. Barcelona: Gedisa, 1995. p. 60-72. 17 GÜNTHER, Gotthard. Life as poly-contexturality. fev. 2004. Disponível em: < http://www.vordenker.de/ggphilosophy/gg_life_ as_polycontexturality.pdf $>$. Acesso em: 13 abr. 2015.

18 ROCHA, Leonel Severo. A produção autopoética do sentido do direito. Direitos Culturais, Santo Ângelo, v. 4, n. 7, p. 13-26, 2009. p. 18.

19 SANTOS, Boaventura de Sousa. A crítica da razãa indolente: contra o desperdício da experiência. São Paulo: Cortez, 2000. gica aristotélica seria monocontextural, ${ }^{20}$ eis que, nessa lógica, apenas o "ser" e o "não ser" seriam possíveis: ou algo é conforme determinada lógica, ou não o é, de forma que uma terceira opção não seria possível. Essa racionalidade - em que pese ser "confinada" a apenas uma contexturalidade - tem sido deveras importante para a história do pensamento humano, mas se torna insuficiente quando se está diante de um cenário hipercomplexo - repleto de variedade de formas de comunicação, bem como de centros emissores de normatividade. ${ }^{21}$ Diversas lógicas e códigos comunicativos seriam possíveis em tal ordem de coisas, formando-se, dessa forma, várias contexturalidades, cada qual com seu respectivo par ordenado "conforme/em desconformidade" - mas que observam uns aos outros, fazendo-se, assim, ligados de certa forma. Nesse passo, observa-se uma estrutura multinivelada de lógicas de extrema complexidade. "Uma contexturalidade é um domínio lógico de uma estrutura estritamente valorada em dois valores, e sua abrangência é determinada pelo uso do TND [Lógica "Tertium Non Datur", sem terceiro elemento possível]". [...] quando se considera, todavia, que o Universo deve ser considerado como uma "intersecção de um número ilimitado de contexturalidades duplamente valoradas", ${ }^{22}$ está-se diante de uma pluralidade de contexturalidades —, ou seja, uma situação de policontexturalidade.

Essa ideia poderia ser desenvolvida um pouco mais para além, quando se toma conhecimento da noção de racionalidade transversal para conversação entre sistemas. A destruição seria o destino da sociedade moderna multicêntrica, formada por múltiplas esferas conflitantes entre si, se não desenvolvessem mecanismos intervinculantes que possibilitam o aprendizado e a influência recíprocos - os acoplamentos estruturais, os quais viabilizam as interferências entre diversos subsistemas sociais. Esses mecanismos, verdadeiras interpenetrações entre sistemas comunicativos, filtram (excluindo certas influências e facilitando outras) e promovem as

20 LUHMANN, Niklas. Como se pueden observar estructuras latentes? In: WATZLAWICK, Pal; KRIEG, Peter. El ojo del observador: contribuciones al construtivismo. Barcelona: Gedisa, 1995. p. 60-72. p. 61.

21 GÜNTHER, Gotthard. Life as poly-contexturality. fev. 2004. Disponível em: <http://www.vordenker.de/ggphilosophy/gg_life_ as_polycontexturality.pdf $>$. Acesso em: 13 abr. 2015. p. 3-4.

22 GÜNTHER, Gotthard. Life as poly-contexturality. fev. 2004. Disponível em: <http://www.vordenker.de/ggphilosophy/gg_life_ as_polycontexturality.pdf $>$. Acesso em: 13 abr. 2015. p. 6. 
influências e os estímulos intersistêmicos recíprocos de maneira duradoura, estável e concentrada, sem que os sistemas percam suas características autonomias. ${ }^{23}$ Aliás, configura-se uma simultânea relação de independência e dependência entre tais sistemas, visto que suas estruturas "passam a ser, mediante os acoplamentos estruturais, relevantes e mesmo indispensáveis à reprodução das estruturas de outro sistema e vice-versa". ${ }^{24}$

Acoplamentos estruturais permitem a construção de racionalidades transversais 25 entre esferas autônomas de comunicação da sociedade mundial, pois são mecanismos que estabelecem intercâmbios de experiência entre diferentes racionalidades parciais, as quais, "conforme o tipo e a singularidade dos respectivos sistemas ou discursos e de acordo com suas relações específicas, variará intensamente na forma e no conteúdo". ${ }^{26}$

Identificar acoplamentos estruturais entre sistemas revela-se estratégia de grande valia num cenário policontextural e hipercomplexo, em que emergem não apenas sistemas comunicativos diferenciados, mas também diversas ordens de caráter normativo; não apenas ordens normativas, mas ordens jurídicas; não apenas ordens jurídicas estatais - ou dependentes da lógica estatal, tais como ordens internacionais (correlatas aos tratados internacionais) e supranacionais (da qual é exemplo significativo a União Europeia), mas também ordens jurídicas não estatais (formadas por laços contratuais entre empresas, num contexto em que ETNs impõem, via contrato, a seus fornecedores, os próprios códigos de conduta corporativos). O simples raciocínio impositivo linear de uma ordem soberana estatal a condutas dos privados pode ainda perdurar, mas não mais se observa como absoluta (de modo como fora outrora).

Sempre que dois sistemas comunicativos interconectam, essa interconexão os torna capazes de desenvolver seus próprios mecanismos de aprendizado e influência estáveis e mútuos. Dessa forma, tem-se que os acopla-

23 LUHMANN, Niklas. La ciencia de la sociedad. Tradução de Silvia Pappe, Brunhilde Erker e Luis Felipe Segura, sob a coordenação de Javier Torres Nafarrate. México: Universidad Iberoamericana, 1996. p. 121.

24 NEVES, Marcelo. Transconstitucionalismo. São Paulo: M. Fontes, 2009. p. 35.

25 WELSCH, Wolfgang. Reason and transition: on the concept of transversal reason. 29 out. 2000. Disponível em: <http://ecommons.library.cornell.edu/bitstream/1813/54/1/Welsch_Reason_ and_Transition.htm>. Acesso em: 13 abr. 2015.

26 NEVES, Marcelo. Transconstitucionalismo. São Paulo: M. Fontes, 2009. p. 38. mentos estruturais constituem racionalidades transversais parciais, sendo que cada uma dessas racionalidades está estruturalmente vinculada às racionalidades particulares, parciais (sistêmicas) confrontadas — sendo, portanto, pontes de transição específicas. ${ }^{27}$

O entrelaçamento entre o Direito e outros sistemas sociais, ou entre várias ordens jurídicas diferenciadas, que permite a construção de uma racionalidade transversal pelo aprendizado recíproco e pelo intercâmbio criativo pode ser denominado Constituição transversal. ${ }^{28}$ Esse conceito implica em externalização e internalização de informações entre os mais diversos sistemas sociais funcionais que primariamente se reproduzem com fundamento em códigos binários de diferentes formas de comunicação.

Identificam-se, assim, relações entre ordens jurídicas diversas, que ocorrem no interior do mesmo sistema funcional da sociedade mundial atual, o Direito - no qual se diferenciam ordens diferenciadas e subordinadas ao mesmo código binário (direito/ não direito), mas com programas e critérios diferentes. Essa diferenciação interna entre ordens jurídicas — que vai para além da segmentação entre ordens estatais — não vem a significar que tais ordens se encontrem desconectadas: há a ligação, por exemplo, entre ordens estatais e internacionais pelo instituto da ratificação; entre ordens estatais, o Direito Internacional Privado tem desenvolvido mecanismos conectivos também.

É peculiar, no entrelaçamento das diversas ordens jurídicas, o fato de haver relativa independência da mediação do sistema político em seu estabelecimento. No âmbito jurídico, são relevantes as "pontes de transições" desenvolvidas diretamente a partir dos respectivos centros dos seus sistemas (os juízes e tribunais). ${ }^{29}$ Com isto, tem-se que não apenas a sociedade mundial, mas também seu Direito é multicêntrico — e os centros das demais ordens jurídicas constituem periferia para o centro de uma dada ordem..$^{30} \mathrm{O}$ caráter multicêntrico, com certa possibilidade de comunicação entre centro(s)

27 NEVES, Marcelo. Transconstitucionalismo. São Paulo: M. Fontes, 2009. p. 42.

28 NEVES, Marcelo. Transconstitucionalismo. São Paulo: M. Fontes, 2009. p. 115.

29 LUHMANN, Niklas. Law as a social system. Tradução para o inglês de Klaus A. Ziegert. Oxford: Oxford University Press, 2004. p. 293.

30 NEVES, Marcelo. Transconstitucionalismo. São Paulo: M. Fontes, 2009. p. 117. 
e periferia(s) de maneira a constituir aprendizado, pode se dar entre as mais diversas categorias de ordens: entre Cortes estatais, entre Cortes estatais e internacionais, etc. Mas esses diálogo entre centros não pressupõe cooperação permanente entre eles, já que vários conflitos são perceptíveis na práxis.

Tem-se, assim, que diferentemente da noção clássica de constitucionalismo, por exemplo, (no qual era possível delimitar as problemáticas relacionadas aos direitos e garantias fundamentais e da limitação e organização estatal às fronteiras nacionais), a noção atual do caráter constitucional (o que pressupõe não apenas a constituição de Estados e organizações interestatais, mas também a emergência de novos centros comunicativos de normatividade jurídica, como aquelas que decorrem das ETNs) exige atualmente a consideração da constitucionalização por outras ordens jurídicas (as que versam sobre Direitos Humanos, por exemplo). Deve-se referir a constitucionalismos nacionais, internacionais, supranacionais e transnacionais - os quais dialogam de maneira a estabelecer processos de aprendizado (seja em situações cooperação, seja em situações de conflito entre ordens). ${ }^{31}$

\section{Conduta das empresas transnacionais e REGULAÇÃO PELO DIREITO ESTATAL}

Apesar de toda a fluidez com que as ETNs operam (o que colocaria suas comunicações, quase automaticamente, no império da lógica acelerada e relativizadora do espaço e do tempo), ainda não se pode absolutizar essa posição - já que, em decorrência do próprio gap entre a lógica fluida e a lógica pretensamente bem delimitada no tempo e no espaço decorrente da soberania —, o fato de uma empresa ser caracterizada como transnacional não a coloca automaticamente em uma espécie de "limbo jurídico", habitando em lugar imaginário na qual a longa manus das jurisdições estatais jamais alcança. Todas ETNs submetem-se, no mínimo, a duas ordens jurídicas: do país onde foram constituídas e mantém a sua sede ("país de origem") e do local onde exercem as suas atividades ("país hospedeiro"). Ambos os Estados possuem a liberdade de utilizarem o seu Direito interno (também chamado de nacional ou doméstico) e os mecanismos que garantem a sua aplicação, com objetivo de

31 NEVES, Marcelo. Transconstitucionalismo. São Paulo: M. Fontes, 2009. p. 119-121. regular o comportamento dessas entidades.

Em primeiro lugar, uma ETN é compelida a adaptar-se ao Direito de um país hospedeiro. Tal situação advém da própria ideia de soberania, que concede a prerrogativa de cada Estado zelar pela ordem em seu território. Nesse cenário regulatório, seria possível defender que bastariam que os países hospedeiros aprovassem legislações de controle da atividade empresária e aplicassem contra ETNs da mesma maneira que fazem com as empresas de atuação exclusivamente interna. Com a adesão da proposta pelos países hospedeiros onde as ETNs exercem suas atividades, cada qual desempenhando o papel de controlar as atividades comerciais que ocorrem em seu território, diminuiriam as possibilidades de condutas indesejadas por essas entidades.

Pensar assim, no entanto, consiste em simplificar o problema. Imaginar que mais de 200 países, com capacidades, realidades e interesses diversos, fiscalizarão essas empresas da mesma maneira, de forma espontânea e sem qualquer estímulo externo, é utópico, para não dizer ingênuo. Existe hoje acirrada disputa por atração de investimento estrangeiro direto que pode forçar a diminuição dos standards regulatórios, em uma espécie de "corrida para o fundo" (race to the bottom). ${ }^{3233}$ De maneira óbvia, o Estado que está buscando incessantemente hospedar uma ETN dificilmente promoverá o endurecimento de seus mecanismos de controle em seu território, com medo de ser preterido na hora da escolha. Nesse contexto e por essas razões, não se pode esperar grandes feitos por parte dos Estados hospedeiros.

Isto abre a possibilidade para que a regulação da conduta das ETNs ocorra, partindo da ação dos Estados investidores, ou seja, aqueles onde estão sediadas essas empresas. ${ }^{34}$ Como esses Estados investidores se benefi-

32 A race to the botton ("corrida para o fundo") ocorre quando os países, em um ambiente de competitividade, não regulam determinadas condutas, passando a tolerar práticas ilícitas para se tornarem mais competitivos. No longo prazo, piora a condição de todos os participantes. Em busca de tornar-se receptor de empresas estrangeiras e investimento externo direto, um Estado pode tornar a sua legislação menos rigorosa e mais permissiva a atividades ilícitas, como no caso da proteção ao meio ambiente, na qual é possível diminuir os requisitos para a concessão de licenças. O problema é que em um ambiente de grande competitividade internacional, muitos países podem ser compelidos a seguirem o exemplo e enfraquecerem seus padrões normativos ainda mais.

33 GUZMAN, Andrew. Why LDCs sign treaties that hurt them? Virginia Journal of International Law, Charlottesville, v. 38, p. 640-688, 1998. p. 671-674.

34 DEVA, Surya. Regulating corporate buman rights violations: human- 
ciam economicamente dessa relação, deveriam ter a responsabilidade de assegurar que suas ETNs não atuem em detrimento do Estado hospedeiro. ${ }^{35}$ Outro aspecto positivo é que se trabalharia com um número muito mais reduzido de países, que são detentores de capacidade de impor sanções efetivas. Essa proposta baseia-se na possibilidade de extensão extraterritorial da norma nacional para ações realizadas em país estrangeiro.

Brownlie ${ }^{36}$ colaciona cinco formas dos Estados exercerem o controle jurídico de condutas. A primeira delas baseia-se no "princípio da territorialidade": os Estados controlam todas as ações que ocorrem em seu território; trata-se de decorrência de sua soberania. Apesar de a territorialidade ser a regra geral, não existe proibição para um Estado que deseja, unilateralmente, criar norma de natureza extraterritorial que regule condutas realizadas no exterior, desde que haja um elemento de conexão que ligue esse fato ao seu interesse nacional e não viole a soberania de outrem. No contexto da "extraterritorialidade", pode recorrer-se ao "princípio da nacionalidade" ou "da personalidade ativa", no qual a norma regula as ações realizadas por seus nacionais (pessoas naturais e jurídicas) produzidas no exterior. Pauta-se na ideia de que os cidadãos devem lealdade ao seu país de origem. ${ }^{37}$ Além disso, pode vincular-se ao "princípio da personalidade passiva" ou "da nacionalidade da vítima", no qual se reprime atos praticados por estrangeiros contra nacionais no exterior; ao "princípio protetor" ou "da segurança”, no qual os Estados fiscalizam as ações praticadas no exterior que possam afetar a sua segurança; e por fim, ao "princípio da universalidade", no qual a natureza grave da conduta impõe que todos os membros da comunidade internacional a reprimam ${ }^{38}$.

izing business. New York: Routledge, 2012. p. 50-51.

35 SORNARAJAH, M. The international law of foreign investment. Cambridge: Cambridge University Press, 2010. p. 159.

36 BROWNLIE, Ian. Princípios de direito internacional público. Lisboa: Fundação Calouste Gulbenkian, 1997. p. 321-326.

37 PIETH, Mark. Article 4: jurisdiction. In: PIETH, Mark; LOW, Lucinda A.; CULLEN, Peter J (Org.). The OECD convention on bribery: a commentary. Cambridge: Cambridge University Press. 2007. p. 267-288. p. 270.

38 Conforme Robinson, "o princípio da justiça universal é baseado na noção de que certos crimes são tão danosos aos interesses internacionais que os Estados podem - ou até mesmo são obrigados a - processar o infrator, independentemente do local do crime ou da nacionalidade do agressor ou da vítima" (ROBINSON, Mary. Foreword. In: MACEDO, Stephen (Org.). The Princeton principles on universal jurisdiction. Princeton: Princeton, 2001. p. 15-18. p. 16). Delitos como pirataria, escravidão, crimes de guerra, crimes contra a paz, crimes contra a humanidade, genocídio e tortura enquadrar-se-iam nesta categoria.
O exercício da extraterritorialidade é limitado pela vedação de interferência na soberania de outros Estados. Sendo assim, os Estados não estão autorizados, sob o pretexto de cumprir norma jurídica nacional de abrangência extraterritorial, a adentrar em território estrangeiro sem o consentimento e realizar atos soberanos, como medidas que necessitam de poder de polícia ou jurisdição. ${ }^{39}$ Em outras palavras, a abrangência extraterritorial da norma nacional não é proibida, podendo regular fatos ocorridos no exterior; mas a sua aplicação e efetivação, que implicam a realização de mecanismos sancionatórios, terá que ser feita dentro de sua circunscrição territorial. Por exemplo, se alguém viola uma norma nacional de um país enquanto está no exterior, na ausência de qualquer cooperação interestatal, só poderá ser coagido a cumprir pena, seja civil ou criminal, quando adentrar no país que emitiu a norma.

O exemplo mais tradicional de extraterritorialidade pode ser encontrado no Direito Criminal. Nesse sentido, é possível existir uma legislação que estabeleça punição de crimes realizados por nacionais no exterior, ou ainda por estrangeiros contra nacionais. Há também os casos que envolvem crimes contra altos funcionários do governo (como chefes do executivo) durante sua estada no exterior, ou que atentem, de alguma forma, contra o patrimônio do Estado, como na produção de danos a bens de representação diplomática. Conforme Sornarajah, ${ }^{40}$ nos países de tradição jurídica de raiz romano-germânica é relativamente comum dispor em seus códigos criminais a extensão extraterritorial da lei penal de acordo com esses moldes ${ }^{41}$. $\mathrm{Na}$ mesma linha, observa-se a existência de legislações que punem nacionais que utilizam serviços de prostituição infantil no exterior. Essas normas estabelecem que o controle de tais condutas não deva ser feito somente no local onde a prostituição existe, geralmente de estrutura estatal deficitária e ineficaz, mas também pelos países onde se originam os turistas. ${ }^{42}$

39 PIETH, Mark. Article 4: jurisdiction. In: PIETH, Mark; LOW, Lucinda A.; CULLEN, Peter J (Org.). The OECD convention on bribery: a commentary. Cambridge: Cambridge University Press. 2007. p. 267-288. p. 269.

40 SORNARAJAH, M. The international law of foreign investment. Cambridge: Cambridge University Press, 2010. p. 165.

41 Além do Brasil (art. $7^{\circ}$ ), existe legislação semelhante em Portugal $\left(\right.$ art. $5^{\circ}$ ), França (do art. 113-6 ao art. 113-12), Alemanha (título I, $\left.\int 5^{\circ}\right)$ e Argentina $\left(\operatorname{art.~} 1^{\circ}\right)$.

42 o caso da legislação na Suécia, Austrália, Canadá, Reino Unido e Estados Unidos. NICHOLS, Philip M. The myth of anti-bribery laws as transnational intrusion. Cornell International Law Journal, 
Nesse passo, não existe óbice para a elaboração de normas nacionais que permitam o controle das operações das ETNs no exterior pelos Estados de origem (investidores). Trata-se de alternativa interessante, uma vez que existe uma tendência natural dos países hospedeiros evitarem a regulação, principalmente por medo de perderem investimentos. ${ }^{43}$ Os principais exemplos vêm dos Estados Unidos. O Direito estadunidense permite que sejam punidas práticas anticoncorrenciais realizadas por afiliadas no exterior ${ }^{44}$, desde que causem efeitos no mercado dos EUA. Também existem leis norte-americanas nos mesmos moldes que proíbem empresas de negociarem com países considerados como inimigos. ${ }^{45}$

Nas últimas décadas, com base na Alien Torts Claim Act - ATCA ("Lei das Ações Cíveis Movidas por Estrangeiros"), que permite que estrangeiro ingresse com ação civil de indenização no judiciário norte-americano por descumprimento de Direito Internacional, ETNs (dos EUA e estrangeiras) estão sendo processadas nos EUA por violações de Direitos Humanos no exterior ${ }^{46}$. $\mathrm{O}$ ingresso de vários casos em cortes norte-americanas ${ }^{47}$

Ithaca, v. 33, p. 627-655, 2000. p. 643.

43 SORNARAJAH, M. The international law of foreign investment. Cambridge: Cambridge University Press, 2010. p. 169.

44 O precedente é o caso United States v. ALCOA de 1945. Na ocasião, vários produtores de alumínio de diferentes acertaram um acordo de cartel na Suíça. Uma empresa norte-americana participou por meio de sua afiliada canadense. Apesar de o ilícito ter se consumado no exterior, a Suprema Corte entendeu que a violação da legislação antitruste praticaria efeitos diretos e substanciais nos EUA. FARIA, José Ângelo Estrella. A aplicação extraterritorial do direito da concorrência. Revista de Informação Legislativa, Brasilia, v. 27, n. 105, p. 19-46, 1990. p. 27.

45 MUCHLINSKI, Peter T. Multinational enterprises and the law. 2. ed. Oxford: Oxford University Press, 2007. p. 115.

46 Neste contexto, a base jurídica está no direito costumeiro e pactício internacional voltado à proteção da pessoa humana que os Estados Unidos estão submetidos, como a Declaração Universal de Direitos Humanos e o Pacto Internacional de Direitos Civis e Políticos.

47 Em Doe v. UNOCAL discutiu-se a atuação de uma ETN norteamericana em Mianmar, que supostamente patrocinou torturas e trabalho forçados. Em Kiobel v. Royal Dutch Petroleum, o processo foi contra uma empresa transnacional de capital britânico e holandês pela participação em um massacre de manifestantes contra a instalação de uma fábrica em Ogoni, Nigéria. Em Bowoto v. Chevron Corp. as acusações foram direcionadas a uma afiliada de empresa norteamericana também pelo uso indevido da força na Nigéria. Em Sarei v. Rio Tinto nacionais de Papua Nova Guiné processaram a empresa transnacional de origem britânica e australiana por terem apoiado ações violentas do governo. Em Wang Xiaoning v. Yahoo! chineses processaram a empresa de serviços de internet por terem repassado informações ao governo chinês, que prendeu e torturou os usuários por atividades supostamente subversivas. Em Sinaltrainal v. CocaCola Company os autores acusaram engarrafadores de refrigerante na Colômbia de colaborarem com as forças paramilitares em atos de violência contra membros de sindicato. e as possíveis condenações decorrentes acarretariam a consolidação do controle extraterritorial da conduta dessas empresas, no que diz respeito à proteção dos Direitos Humanos. Outros países seguiram o exemplo dos EUA e passaram a exercer jurisdição sobre as ações de suas ETNs no exterior a partir construções jurisprudenciais, como é o caso da Austrália, Países Baixos e Reino Unido. Após anos de batalhas judiciais, em abril de 2013, a Suprema Corte norte-americana decidiu que a $A T C A$ não é aplicável a atos realizados no exterior, devendo o descumprimento de Direito Internacional ter ligação com o solo norte-americano, sob pena de ocorrer violação de soberania estrangeira, em tentativa de barrar o elevado número de ações propostas nos últimos anos.

Pode-se observar, portanto, que mesmo estando em crise a ideia de soberania na atualidade, esta ainda confere aos Estados aptidão para regular condutas das ETNs relacionadas aos seus territórios. Porém, as múltiplas possibilidades de regulação (ou seja, a falta de uniformidade) que podem surgir na realidade (pois, para cada Estado, tem-se uma cultura jurídica própria), somadas às disputas internacionais pela atração de ETNs, fazem com que se observe não um incremento na normatização das suas condutas. Antes, é notável um fenômeno oposto, de desregulamentação.

Ainda, nessa mesma senda, considera-se que as raras possibilidades de atuação extraterritorial dos Estados demonstram que a regulação estatal das condutas das ETNs deve ser complementada por outras estratégias nesse mesmo sentido. A empolgação inicial representada pela utilização da $A T C A$ em tribunais norte-americanos, que poderia consolidar não apenas o alcance extraterritorial da norma, mas a aplicação do "princípio da universalidade" para julgar e punir os desvios das ETNs, foi claramente soterrada pela dura realidade fática, governada pelos interesses econômicos das grandes corporações e das nações desenvolvidas. Daí a consideração da necessidade de se tratar acerca de estratégias internacionais de regulação.

\section{Regulação PELO diREITO INTERNACIONAL dAS CONDUTAS DAS EMPRESAS TRANSNACIONAIS}

O entendimento sobre a necessidade de controle das atividades das ETNs pelos países-sede não deve ser visto, contudo, como descoberta de uma "panaceia". É 
fácil reconhecer, em tese, a existência de uma obrigação desses países em fiscalizarem suas ETNs; difícil, porém, é operacionalizar essa afirmativa. Apesar de a previsão da extraterritorialidade de suas normas ser ato unilateral que parte do próprio Estado no exercício de sua soberania, não há nada que simplesmente force a fazê-lo. É forte a tendência, dentre Estados poderosos economicamente, em permanecerem inertes, objetivando proteger as práticas comerciais de suas ETNs, ainda que essas ações prejudiquem os hospedeiros.

Conforme Nichols ${ }^{48}$ existe dificuldade em se pensar na regulação de ETNs apenas sob a lógica exclusiva do Direito nacional. Enquanto as estruturas empresárias são formadas sem qualquer consideração às barreiras políticas, o Direito nacional enfrenta os obstáculos fronteiriços. No mesmo sentido, Muchlinski ${ }^{49}$ entende que existe um descompasso entre a amplitude gerencial e operacional das ETNs e o alcance jurisdicional do Estado que procura regulá-las. A estratégia de utilização dos Direitos nacionais aplicados de forma territorial ou extraterritorial enfrenta o problema da assimetria dessas manifestações jurídicas. Não há nada o que assegure que os Estados irão efetivamente coibir essas condutas e, caso o façam, não há garantias de que seguirão o mesmo padrão regulatório. A utilização do Direito Internacional pode representar o afastamento da dependência de medidas unilaterais estatais e a construção de um regime jurídico multilateral capaz de coibir as más condutas empresárias em qualquer lugar do mundo. Nesse contexto, seriam depuradas as pretensões individualistas dos Estados quanto ao tema, buscando-se uma situação favorável para a comunidade internacional.

Historicamente, o Direito Internacional foi criado para regular a conduta dos Estados e garantir a coexistência pacífica no plano internacional. ${ }^{50}$ Difere do Direito nacional na produção e aplicação de normas, uma vez que não existe aqui órgão externo centralizado, restando aos próprios Estados a realização da sanção, tal qual o Direito de uma sociedade primitiva. ${ }^{51}$ Com base

48 NICHOLS, Philip M. The myth of anti-bribery laws as transnational intrusion. Cornell International Law Journal, Ithaca, v. 33, p. 627-655, 2000. p. 628.

49 MUCHLINSKI, Peter T. Multinational enterprises and the law. 2. ed. Oxford: Oxford University Press, 2007. p. 115.

50 SHAW, Malcolm N. Direito internacional. São Paulo: M. Fontes, 2010. p. 37.

51 "Como todo mundo sabe, o sistema normativo internacional [...] é menos elaborada e mais rudimentar que as ordens jurídicas domésticas - o que, é claro, não significa que é inferior ou menos em sua expansão e desenvolvimento, o Direito Internacional contemporâneo não se preocupa apenas com as relações interestatais, mas também com a conduta dos Estados frente. Questões que antes eram consideradas domésticas e submetidas apenas ao Direito interno (e.g. Direitos Humanos e Direito Ambiental) encontram-se submetidas a normas internacionais. ${ }^{5253}$ Hoje, qualquer assunto pode ser suscetível de regulação pelo Direito Internacional desde que seja de interesse da comunidade internacional. ${ }^{54}$ Nesse contexto, não existem óbices para a criação de normas internacionais com objetivo de regular as ETNs.

A operacionalização dessa norma, entretanto, constitui um desafio. Ainda que a norma internacional seja voltada para indivíduos (ou uma coletividade, no caso a empresa), não é possível afastar a figura do Estado desse processo. Não se pode esquecer que são os Estados, e não as ETNs, os sujeitos típicos do Direito Internacional. ${ }^{55}$ Conforme Shaw, ${ }^{56}$ a razão disso reside nas falhas que as ETNs apresentam nos principais testes para averiguação de personalidade jurídica internacional, como a capacidade de celebrar tratados internacionais, o amplo acesso a tribunais internacionais e a possibilidade de ser punida por eles. Em relação ao segundo

‘jurídico’ que eles: são apenas diferentes” (WEIL, Prosper. Towards relative normativity in international law? The American Journal of International Law, Washington, v. 77, n. 3, p. 413-442, 1983. p. 413-414). No direito de uma sociedade primitiva, o indivíduo que tinha seus interesses juridicamente protegidos violados estava autorizado pelo próprio ordenamento jurídico a tomar as medidas coercitivas previstas. É a autotutela ou justiça pelas próprias mãos. Com a organização da estrutura estatal, a autotutela deixou de ser permitida no direito doméstico e a sanção passou a ser aplicada por esta estrutura centralizada e externa. Não existe tal órgão nas relações entre Estados (KELSEN, Hans. Derecho y paz, en las relaciones internacionales. 2. ed. Mexico: Fondo de Cultura Económica, 1986).

52 SHELTON, Dinah. International law and 'relative normativity'. In: EVANS, Malcolm (Org.). International law. 2. ed. Oxford: Oxford University Press, 2006. p. 159-184. p. 162.

53 Até o século XX, praticamente todos os tratados eram bilaterais e dispunham apenas de relações jurídicas interestatais, como relações diplomáticas, direito marítimo, comércio e extradição. Hoje, o número de instrumentos internacionais cresceu exponencialmente e regulam vários assuntos, geralmente de maneira multilateral (SHELTON, Dinah. International law and 'relative normativity'. In: EVANS, Malcolm (Org.). International law. 2. ed. Oxford: Oxford University Press, 2006. p. 159-184. p. 162).

54 KELSEN, Hans. Princípios do direito internacional. Ijuí: Unijuí, 2010. p. 250.

55 ALVAREZ, Jose E. Are corporations "subjects" of international law? Santa Clara Journal of International Law, Santa Clara, v. 9, n. 1, p. 01-36, 2011. p. 34.

56 SHAW, Malcolm N. Direito internacional. São Paulo: M. Fontes, 2010. p. 186. 
requisito, observa-se que existe um acesso limitadíssimo a dois tribunais, no entanto, as ETNs participam apenas como autores e nunca como réus, o que demonstra a natureza incompleta no cumprimento do pretenso requisito. ${ }^{57}$ Assim, na presença de norma internacional de matéria relacionada às ETNs, são os Estados os sujeitos internacionais que possuem a obrigação de garantir direitos e exigir deveres dessa estrutura empresarial que opera em seu território, utilizando-se de seus mecanismos coercitivos. ${ }^{58}$

Não existe impedimento para que um Estado aplique diretamente uma norma internacional em ETNs. Contudo, com a expansão do Direito Internacional em direção a novos temas (tidos tradicionalmente como domésticos), é comum encontrar normas internacionais incompletas, ${ }^{59}$ que exigem a conversão ou criação de Direito interno, com objetivo de permitir as devidas adaptações de acordo com a realidade jurídica do Estado vinculado. Aqui, o Direito Internacional pode ser instrumento para reforma do Direito e das instituições nacionais, possibilitando a absorção de experiências jurídicas testadas em outros países e difundidas mediante o consenso da comunidade internacional. Caso o procedimento legislativo interno não seja realizado, dita cláusula do tratado fica prejudicada até que as medidas legislativas nacionais sejam tomadas. Enquanto as normas domésticas não são criadas, cabe aos demais Estados avaliarem a situação do cumprimento do tratado e realizarem pressões políticas para que o país signatário tome as devidas providências. Um exemplo de norma internacional que carece de execução automática são os tratados que versam sobre Direito Penal e crimes transnacionais. ${ }^{60}$ Incapazes de criminalizarem condutas, pois

57 O primeiro é o International Centre for Settlement of Investment Disputes (Centro Internacional para Arbitragem de Disputas sobre Investimentos), corte arbitral ligada ao Banco Mundial que busca resolver lides envolvendo investimento estrangeiro. O segundo é o Iran-United States Claim Tribunal, instituição criada mediante acordo entre Irã e Estada Unidos para resolver os conflitos envolvendo a nacionalização de ativos norte-americanos após a Revolução Iraniana.

58 NASSER, Salem Hikmat. Fontes e normas do direito internacional: um estudo sobre a soft law. 2. ed. São Paulo: Atlas, 2006. p. 90.

59 KELSEN, Hans. Princípios do direito internacional. Ijuí: Unijuí, 2010. p. 493.

60 É o caso da Convenção das Nações Unidas contra o Crime Organizado Transnacional e seu Procolo Relativo à Prevenção, Repressão e Punição do Tráfico de Pessoas, em Especial Mulheres e Crianças; Convenção contra a Tortura e Outros Tratamentos ou Penas Cruéis, Desumanos e Degradantes; Convenção Internacional para a Proteção de Todas as Pessoas contra os Desaparecimentos Forçados; Convenção para a Supressão do Financiamento do Ter- seria afronta à soberania nacional, limitam-se em criar a obrigação para os Estados de alterarem a sua legislação penal de acordo com o tratado, de modo a uniformizar a repressão penal frente a crimes de interesse internacional.

É necessário analisar qual fonte de Direito Internacional seria a mais adequada para tratar sobre ETNs. O costume internacional, prática reiterada de atos aceitos como Direito pelos Estados, foi a única fonte durante séculos, quando o Direito ainda era predominantemente não escrito. ${ }^{61}$ Com o tempo, processos de codificação do Direito, os Estados passaram a firmar acordos escritos, estipulando normas jurídicas a serem observadas pelos signatários, na forma de tratados internacionais. Ainda que não exista hierarquia entre as duas fontes, não se pode negar que a clareza e estabilidade que é inerente a um documento escrito alçaram o tratado internacional à posição de principal recurso jurídico, vide o crescimento exponencial de número de acordos nos últimos dois séculos e o processo de codificação dos costumes internacionais. Uma norma jurídica com temática afeita às ETNs parece ser mais compatível com uma manifestação pactícia, pois bastaria o consenso dos Estados para a sua criação.

No entanto, as tentativas de criar um tratado internacional definitivo sobre a responsabilidade das ETNs fracassaram. Os tratados bilaterais de investimento, que poderiam dispor sobre o assunto, estabelecem apenas direitos às ETNs (como proteção ao investimento e garantia de reparação econômica em caso de expropriação), sem a materialização de obrigações das estruturas empresárias frente ao Estado hospedeiro. $\mathrm{Na}$ década de 1970, após o não cumprimento das promessas de desenvolvimento econômico e social do processo de liberalização do investimento estrangeiro direto, muitos países periféricos adotaram uma postura crítica em relação às ETNs, vistas como instrumento de dominação econômica e intervenção política. ${ }^{62}$ A propagação do modelo neoliberal nos anos 90 tornou os países mais interessados em atraírem investimento estrangeiro direto a qualquer custo e menos preocupados com as possí-

rorismo, e as convenções internacionais e regionais contra a corrupção, que serão estudados com detalhes ao longo da pesquisa.

61 MALANCZUK, Peter. Akehurst's modern introduction to international law. 7. ed. New York: Routledge, 1997. p. 36.

62 KELLER, Helen. Codes of conduct and their implementation: the question of legitimacy. In: WOLFRUM, Rüdger; VOLKER, Röben (Org.). Legitimacy in international law. Berlin: Springer, 2008. p. 219-298. p. 255. 
veis consequências negativas desses empreendimentos, o que sepultou a criação do tratado internacional.

As pesquisas realizadas nas últimas décadas têm incluído nova fonte jurídica de Direito Internacional, nomeada de soft law ("Direito suave" ou "flexível"). De acordo com Nasser ${ }^{63}$ são normas de "linguagem vaga, ou de noções de conteúdo variável ou aberto, ou que apresentam caráter de generalidade ou principiológico que impossibilite a identificação de regras específicas e claras". Uma característica sua que contrasta com as outras normas (classificadas como hard law, "Direito duro" ou "inflexível") consiste no afastamento de métodos tradicionais de coerção para o seu cumprimento, fundamentados em sanções, preferindo apostar em mecanismos mais brandos, estimulando, por exemplo, a prática da mediação e conciliação. ${ }^{64}$ Por vezes, parecem não ter aplicação obrigatória, preocupando-se mais em "sugerir" ou "orientar" a melhor conduta a ser adotada pelo destinatário, capaz de produzir a menor lesão social possível, do que prever consequência clara para o descumprimento da norma. Apesar de o conceito não se limitar ao Direito Internacional, o soft law costuma ser associado a essa manifestação jurídica.

Shelton $^{65}$ classifica como soft law qualquer instrumento internacional escrito que descreve condutas e princípios importantes a serem adotados pelos Estados, sem contudo, dispor sobre sanções diretas em caso de inobservância. Ao contrário dos tratados internacionais (de natureza de hard law), são normas não vinculativas, não podendo ser exigido juridicamente o seu cumprimento pelos demais membros da comunidade internacional. Tal atributo é particularmente interessante aos Estados, que podem aderir à norma sem o medo de descobrirem-se incapazes de cumprir seus dispositivos no futuro. Aqui, destaca-se a sua flexibilidade, que não exige procedimentos formais para criação e alteração, ao contrário dos tratados internacionais. Podem ser citadas como exemplos de normas internacionais de natureza de soft law as manifestações não obrigatórias de organizações internacionais; códigos de conduta ou "leis modelos" emitidos por essas instituições; e declarações

63 NASSER, Salem Hikmat. Fontes e normas do direito internacional: um estudo sobre a soft law. 2. ed. São Paulo: Atlas, 2006. p. 25.

64 NASSER, Salem Hikmat. Fontes e normas do direito internacional: um estudo sobre a soft law. 2. ed. São Paulo: Atlas, 2006. p. 25.

65 SHELTON, Dinah. International law and 'relative normativity'. In: EVANS, Malcolm (Org.). International law. 2. ed. Oxford: Oxford University Press, 2006. p. 159-184. p. 180 conjuntas de vários países ao final de um encontro. $\mathrm{O}$ Direito Internacional Econômico e o Ambiental têm sido as principais áreas que recepcionaram as práticas de soft law. ${ }^{66}$

Muitas normas internacionais de soft law são acompanhadas por mecanismos de monitoramento gerenciados pelos aderentes ao documento. Em um procedimento de "avaliação mútua entre pares", os Estados registram as violações e avaliam o cumprimento do soft law pelos colegas, ao mesmo tempo em que são avaliados. Ao final, discutem os desafios a serem enfrentados e as possíveis medidas a serem tomadas para o aperfeiçoamento das condutas. Isto demonstra o caráter educativo do soft law, ao invés de concentrar-se na punição dos infratores, busca meios alternativos de sanção, ${ }^{67}$ operando em uma zona cinzenta entre Direito e Política internacionais. ${ }^{68}$ Na manutenção de um canal de diálogo e negociação, a sanção torna-se indireta, na forma de pressão e constrangimento exercido pelos demais pactuantes cumpridores da norma.

Um ponto importante diz respeito à interação dinâmica entre o soft law e os instrumentos pactícios. É comum a edição prévia de normas de soft law como teste de aceitação de regras e princípios para depois elaborar um tratado internacional sobre o assunto. Outra função interessante a criação de tratados internacionais que estipulam apenas aspectos jurídicos gerais, deixando para o soft law o seu detalhamento. ${ }^{69}$ Evita-se, assim, o desgaste político na elaboração de emendas ou um novo instrumento pactício, deixando o Direito Internacional mais flexível, dinâmico e adaptável às mudanças. É imperativo ressaltar que o soft law também conserva o mesmo ímpeto transformador dos tratados internacionais em relação as ordens internas dos países vinculados, podendo estimular o surgimento de novas experiências de Direito nacional.

Os movimentos contestadores da década de 1970 podem não ter sido capazes de criar um tratado internacional, mas impulsionaram o desenvolvimento de soft

66 SHAW, Malcolm N. Direito internacional. São Paulo: M. Fontes, 2010. p. 93.

67 CHINKIN, C. M. The challenge of soft law: development and change in international law. International and Comparative Law Quarterly, Cambridge, v. 38, p. 850-866, 1989. p. 862.

68 MALANCZUK, Peter. Akehurst's modern introduction to international law. 7. ed. New York: Routledge, 1997. p. 54.

69 SHELTON, Dinah. International law and 'relative normativity’. In: EVANS, Malcolm (Org.). International law. 2. ed. Oxford: Oxford University Press, 2006. p. 159-184. p. 181. 
law inédita sobre o assunto. Em 1976, a OCDE elaborou as "Diretrizes para Empresas Multinacionais". No ano seguinte, foi criada a "Declaração Tripartite de Princípios sobre Empresas Multinacionais e Política Social" da OIT, que possui como objetivo difundir o respeito ao Direito do Trabalho pelas ETNs. Em 2003, a ONU criou as "Normas sobre a Responsabilidade das Empresas Transnacionais e Outros Empreendimentos em Relação aos Direitos Humanos". Tais normas de soft law dispõem sobre o dever dos Estados em proteger pessoas de violações de Direitos Humanos praticados por empresas, inclusive atos ilícitos produzidos no exterior, no que tange às ETNs domiciliadas em seu território.

Muchlinski ${ }^{70}$ observa que, no que diz respeito à temática de regulação da conduta de ETNs, existe uma predominância no uso do soft law em comparação com os tratados internacionais. $\mathrm{O}$ autor defende que essa escolha não é arbitrária e segue interesses econômicos dos Estados investidores. Em temas sensíveis para esse grupo, como comércio internacional e investimento estrangeiro direto, as fontes jurídicas apresentam natureza formal e obrigatória (hard law), como é o caso dos instrumentos bilaterais de proteção ao investimento estrangeiro direto. Em outra banda, no que se refere às questões ligadas à responsabilidade das ETNs frente às sociedades em que atuam, predominam-se fontes de caráter informal e de observância facultativa no plano internacional (soft law).

O que transparece é que as potências dominantes das relações internacionais, apesar de exigirem práticas de responsabilidade corporativa no seu ambiente interno, relutam em garantir que suas ETNs não vão se comportar de maneira inadequada nos Estados hospedeiros, com medo que isto possa prejudicar seus interesses comerciais. ${ }^{71}$ A cobrança crescente da sociedade civil internacional, cada vez mais consciente da má conduta das ETNs, culminou na criação de algumas experiências normativas de natureza de soft law. Tais iniciativas, no entanto, parecem, por vezes, ser "cortinas de fumaça" para mascarar o problema, uma vez que os países ricos evitam claramente o reconhecimento de responsabilidade empresária por meio de normas imperativas de hard

70 MUCHLINSKI, Peter T. Multinational enterprises and the law. 2. ed. Oxford: Oxford University Press, 2007. p. 110.

71 KAMMINGA, Menno T.; ZIA-ZARIF, Saman. Introduction. In:__ (Org.). Liability of multinational corporations under international law. Haia: Kluwer Law International, 2000. p. 01-16. p. 07-08. law. ${ }^{72} \mathrm{Na}$ mesma linha e em tom crítico, Adeyeye ${ }^{73}$ reconhece que a soft law pode ser inadequada e ineficiente no campo da responsabilidade das ETNs, necessitando-se de hard law nessa área.

Sendo assim, tem-se que às estratégias internas estatais de regulação de condutas das ETNs devem ser somadas estratégias internacionais. Não sendo suficientes aquelas, estas podem representar importante complemento. Contudo, conforme observado acima, mecanismos normativos internacionais apresentam sérios defeitos: inércia dos países mais fortes (geopolítica e economicamente) em regular de modo efetivo as ETNs neles sediadas; falta de mecanismos coercitivos que venham a pressionar os Estados no intuito de fazê-lo; típica incompletude textual das normas internacionais; inércia legislativa interna dos Estados em implementarem as recomendações frequentes em instrumentos normativos internacionais. Caso existisse um tratado internacional compreensivo, capaz de dispor sobre a responsabilidade das ETNs, poderia ser um primeiro passo em direção à fiscalização uniforme da má conduta dessas entidades na seara internacional. No entanto, tal instrumento não se concretizou — nem mesmo existem previsões otimistas para a sua elaboração. A emergência do soft law na área pode até representar uma tentativa de suprir tal lacuna; porém, a aplicação desse tipo de norma, que proporciona uma falsa impressão de segurança — uma vez que se trata de norma fluida e incerta — também constitui barreira para que novas experiências jurídicas pactícias sejam testadas.

A gama de vícios recém-descrita e listada faz resplandecer a necessidade de, às estratégias estatais e internacionais em regular a conduta das ETNs, serem somadas outras, ainda. Eis a razão pela qual se dedica a continuidade deste trabalho em descrever uma importante (e interessante) possibilidade de complemento àquelas ordens jurídicas: as ordens jurídicas não-estatais surgidas dos mecanismos de autorregulação verificáveis, atualmente, e relacionadas às ETNs.

72 SORNARAJAH, M. The international law of foreign investment. Cambridge: Cambridge University Press, 2010. p. 146-149.

73 ADEYEYE, Adefolake. Corporate responsibility in international law: which way to go? Singapore Yearbook of International Law, Singapore, v. 11, p. 141-161, 2007. p. 39. 


\section{Possibilidades de AUtORREgUlação dAS EMPRESAS TRANSNACIONAIS}

Uma análise descuidada encerraria a ideia tradicional de fontes de Direito. No entanto, é inegável que o fenômeno jurídico possui novas e complexas nuances na contemporaneidade, que impactarão diretamente nas estratégias regulatórias, envolvendo condutas das ETNs. Como se sabe, a formação dos Estados nacionais implicou a reivindicação do monopólio da criação do Direito (nacional ou interno) por essas estruturas. No plano externo, esse esquema também é reproduzido, pois os Estados reservaram a prerrogativa de serem os produtores de suas próprias normas jurídicas. Hoje, esse modelo tradicional é claramente tensionado pelos processos econômicos, políticos e sociais. A gradual integração e interdependência dos mercados nacionais e a proliferação do modelo capitalista neoliberal a partir da globalização propõem um Estado mínimo e de pouca intervenção, capaz de transferir uma série de responsabilidades do setor público para o setor privado, ${ }^{74}$ incluindo-se a produção e aplicação das normas jurídicas.

O processo contemporâneo de "privatização" do Direito vincula-se às ideias de pluralismo jurídico e de policontexturalidade, as quais contemplam possibilidades de existência de ordens jurídicas não estatais, administrado pelos próprios atores privados, que são responsáveis pela produção e aplicação das próprias normas, em uma espécie de "autorregulação" de suas condutas. Não se trata de aceitar um modelo necessariamente economicista e conduzido por agentes de mercado, mas reconhecer a existência e importância de normas espontâneas e descentralizadas, fruto do exercício da autonomia social e baseadas em ações consensuais. Tais normas estão, em princípio, desprendidas de processos políticos centralizadores das estruturas estatais, passando a ser geridas pela própria sociedade civil ${ }^{75}$ situação que as aproxima das necessidades de diferentes segmentos sociais.

É importante dizer que esse possível "Direito não estatal" não se encontra isolado de outros sistemas jurídicos (Direito nacional e internacional) e sociais (como por exemplo, economia e política), recebendo estímulos

74 TEUBNER, Gunther.. After privatization? the many autonomies of private law. Current Legal Problems, London, v. 51, n. 1, p. 393-424, 2012. p. 393.

75 TEUBNER, Gunther.. After privatization? the many autonomies of private law. Current Legal Problems, London, v. 51, n. 1, p. 393-424, 2012. p. 399. externos. Isto é comprovado com a difusão da noção de compliance no mundo dos negócios, fenômeno com consequências relevantes para o Direito. Certamente influenciado pelas ideias contemporâneas de responsabilidade empresária e boa governança, compliance advém do verbo da língua inglesa to comply, o qual, em linhas gerais, significa "cumprir" ou "estar em conformidade" com algo, sendo comumente utilizado no ambiente empresarial como "cumprimento de norma jurídica" ${ }^{76}$ A ideia consiste em criar mecanismos dentro da empresa para assegurar o "cumprimento prévio" de normas jurídicas estatais, de modo a diminuir o risco de ser punido no futuro em alguma jurisdição. A cultura do compliance é implementada por meio de um "programa", um conjunto de ações planejadas por uma organização para assegurar, mediante criação de estruturas e mecanismos, o seguimento de uma certa conduta. Órgãos de fiscalização para a responsabilidade empresária (como no âmbito ambiental, tributário, anticorrupção, etc.) de diversos países costumam abrandar suas sanções frente à comprovação da existência de efetivos programas de conformidade (compliance), como uma maneira de estímulo ao processo de "privatização" da regulação e aplicação do Direito.

Apesar de muitas vezes originar-se de um estímulo externo - qual seja, uma tentativa de escapar das tradicionais sanções estatais programas de compliance conduz a processos de autorreprodução de subsistemas jurídicos próprios, compostos por normas jurídicas e suas respectivas sanções, criados e administrados por determinadas organizações empresárias. No que tange às ETNs, em razão da amplitude de suas atividades, esse sistema de regulação não estatal adquire dimensões globais, ${ }^{77}$ atingindo os funcionários dessas empresas e seus parceiros comerciais.

A base de um programa de compliance costuma ser a manutenção de um código de conduta e ética elaborado por uma determinada empresa e direcionado aos seus funcionários. Em 1977, a General Motors era a maior ETN com atuação na África do Sul durante o regime do apartheid. À época articulava-se um forte movimento de desinvestimento no país para pressionar uma reforma

76 KINGSBURY, Benedict. The concept of compliance as a function of competing conceptions of international law. Michigan Journal of International Law, Ann Arbor, v. 19, p. 345-372, 1998. p. 345-346.

77 MUCHLINSKI, Peter T. Multinational enterprises and the law. 2. ed. Oxford: Oxford University Press, 2007. p. 113. 
política na região. O reverendo Leon Sullivan, membro do conselho de administração da companhia, ofereceu uma alternativa: a criação de um código de conduta interno que impedisse práticas racistas. O conjunto de princípios, conhecidos como Sullivan Principles, foi bem recebido pelo mundo empresarial, tendo sido reproduzido em vários códigos de conduta. Outra iniciativa semelhante foi o MacBride Principles, voltados ao respeito aos direitos dos trabalhadores na Irlanda no Norte (1984). Uma das primeiras ETNs a possuírem um código próprio foi a britânica Royal Dutch Shell. ${ }^{78}$ Hoje, várias ETNs mantêm os seus códigos. Tais normas também são comumente reproduzidas em contratos com seus parceiros comerciais, com o objetivo de alcançar também suas condutas. Esses códigos e os respectivos mecanismos de monitoramento estão revestidos de juridicidade, uma vez que descrevem condutas a serem observadas, tornando-se uma espécie de "lei interna", de cumprimento obrigatório no âmbito da empresa (incluindo ETNs). A possível sanção para o descumprimento dessa norma reside em medida disciplinar (como advertência, suspensão ou demissão das ETNs) aplicada pela empresa em seu funcionário ou rompimento de contrato, quando se tratar de um parceiro comercial.

Robé $^{79}$ fornece como exemplo a previsão no Código de Trabalho francês (Code du Travai) da possibilidade de manutenção de "regulamentos internos" (règlements intérieurs) por empresa. Seria a prova de reconhecimento, por parte do direito estatal francês, da validade jurídica dos códigos empresariais internos. $\mathrm{O}$ autor observa, contudo, que nas últimas décadas essa delegação legislativa tem perdido espaço, sendo permitida nos dias atuais apenas para grandes empresas e em assuntos restritos (disciplina, higiene e segurança).

Observa-se que cada ETN, com seus programas de compliance e códigos de conduta em geral, constitui um subsistema jurídico único. Contudo, além das interações com os sistemas tradicionais de Direito (Direitos nacionais), existe uma interação entre as próprias empresas que, por meio de ações em conjunto, podem conduzir a uma uniformização desses Direitos não estatais. Teu-

78 EINHORN, Aaron. The evolution and endpoint of responsibility: the FCPA, SOX, socialist-oriented governments, gratuitous promises, and a novel CSR code. Denver Journal of International Law and Policy, Denver, v. 35, p. 509-545, 2007. p. 537-538.

79 ROBÉ, Jean-Philippe. Multinational enterprises: the constitution of a pluralistic legal order. In: TEUBNER, Gunther (Org.). Global law without a state. Vermont: Dartmouth, 1997. p. 45-77. p. 62-65. bner $^{80}$ aponta que os atores privados podem criar laços transnacionais e elaborarem um Direito totalmente independente das estruturas estatais e de aplicação global (um "Direito global" ou "anacional", em oposição a um Direito "inter-nacional”, entre Estados). Dois exemplos podem ser citados de um Direito não estatal de alcance transnacional. ${ }^{81} \mathrm{O}$ primeiro é a nova lex mercatoria, representada pelo conjunto de normas criadas de maneira independente pelas empresas para a prática do comércio internacional na contemporaneidade, baseando-se nos usos e costumes comerciais reconhecidos mundialmente. Manifesta-se na elaboração e difusão de "contratos padronizados" (incoterms), idealizados e atualizados pela Câmara Internacional do Comércio, organização internacional não governamental mantida pelo meio empresário. O outro exemplo é o Direito desportivo internacional (lex sportiva internationalis), organizado pelas entidades esportivas privadas internacionais, como a Federação Internacional de Futebol (FIFA). Enquanto o Estado representa um ente estranho a esses temas e repleto de limitações em seu alcance (como o princípio da territorialidade), os agentes produtores dessas normas estão plenamente inseridos em seus segmentos sociais, o que torna essa manifestação jurídica deveras atrativa.

É importante dizer que a autorregulação e a possibilidade de aplicação de um "Direito não estatal" pelas ETNs não são, absolutamente, livres de críticas. Apesar de sua existência ser reconhecida nas pesquisas contemporâneas, sua eficácia costuma ser amplamente questionada, de modo a colocá-la sempre submissa a um Direito estatal nacional. Nesse sentido, Murphy, ${ }^{82}$ ao tratar da autorregulação de ETNs, não desvincula esse sistema jurídico da necessidade de intervenção estatal. O autor defende que é imprescindível que os Estados estipulem oficialmente os parâmetros mínimos para a autorregulação, fiscalizem se as empresas estão efetivamente aplicando seus códigos de conduta e concedam algum tipo de benefício para aquelas que demonstrarem cumprimento de suas normas, como diminuição de pena em caso de sanção estatal ou acordo favorável. Se

80 TEUBNER, Gunther. A bukowina global sobre a emergência de um pluralismo jurídico transnacional. Impulso, Piracicaba, v. 13, n. 33, p. 09-31, 2003. p. 11-13.

81 TEUBNER, Gunther. A bukowina global sobre a emergência de um pluralismo jurídico transnacional. Impulso, Piracicaba, v. 13, n. 33, p. 09-31, 2003. p. 11.

82 MURPHY, Sean D. Taking multinational corporate codes of conduct to the next level. Columbia Transnational Law, New York, v. 43, p. 01-55, 2005. p.44-53. 
isso não for feito, os códigos de conduta e os mecanismos de compliance viram meros instrumentos de retórica. Muchlinski, ${ }^{83}$ em seu turno, critica abertamente as propostas de autorregulação, taxando-as de neoliberais. Sua denúncia é no sentido de que se trata claramente de uma estratégia para retirar os Estados de alguns setores de regulação, substituindo-os por regramentos gerenciados pelas próprias ETNs, condizentes com os próprios interesses dessas organizações empresárias e do capital internacional.

Haja ou não críticas tecidas contra a autorregulação das ETNs, há de se convir que teorias monistas, unicistas e juspositivistas não mais se adéquam a uma realidade cada vez mais complexificada por novos atores, novas interações e novos centros emissores de normatividade. Socialmente pode se observar como construtiva a criação, com vistas a um incremento no compliance, de ordens jurídicas relacionadas à autorregulação das ETNs, e não como deletéria para a soberania estatal. Aliás, acredita-se, aqui, em um posicionamento teórico de acordo com o qual uma teoria da reflexividade entre ordens estatais e não estatais - teoria esta que verse acerca da possibilidade de aprendizado e complementação na regulação entre essas ordens de origem diversa.

Esse aprendizado se daria nas possibilidades de observação mútua entre ordens: a operabilidade das ordens jurídicas estatais poderia ser melhor contextualizada se estas observarem como as ETNs vêm regulando assuntos diretamente relacionados às suas condutas; por outro lado, as ordens jurídicas não estatais, ao observarem os postulados próprios das ordens estatais (principalmente aqueles fundados em princípios e procedimentos normativos democráticos) para formularem seus mecanismos de autorregulação, podem incrementar ainda mais sua compliance, já que se aproximariam daqueles interesses sociais já cristalizados em ordens positivas.

\section{Considerações finais}

Notadamente a atualidade passa por modificações drásticas, decorrentes das potencializações que as tecnologias de informação, comunicação, transporte, produção e controle de processos. Essas transformações, muito mais (porém, não unicamente) notáveis na Eco-

83 MUCHLINSKI, Peter T. Multinational enterprises and the law. 2. ed. Oxford: Oxford University Press, 2007. p. 113. nomia, fazem com que os postulados da Modernidade, no tocante à Política e ao Direito, sejam totalmente questionáveis: monopólio do Estado como centro emissor de normatividade política e jurídica; supremacia desse mesmo Estado no cenário geopolítico e na tutela dos bens jurídicos considerados relevantes socialmente; dentre outros correlatos.

A emergência de ETNs, atores privados de abrangência e relevância econômicas e políticas globais, deve ser analisada detalhadamente no tocante ao Direito. Não se trata de desconsiderar a figura do Estado na regulação e na tutela das suas condutas: essa figura não está relegada ao desuso, sendo muitas vezes utilizada para atender aos interesses das próprias ETNs. Ademais, essas últimas também dependem da atuação estatal para a sua instalação, funcionamento e produção, demonstrando-se que não há um esvaziamento da sua função normativa: esta deve ser, isto sim, repensada conforme a policontexturalidade e a hipercomplexidade — a fim de que não se estanquem e obliterem as possibilidades regulatórias públicas significativas.

Por outro lado, apesar dos insucessos até hodiernamente bastante verificáveis nas experiências regulatórias das ETNs mediante estratégias de Direito Internacional, trata-se de área longe de ser desconsiderada para esses propósitos. A análise dessas estratégias, dos seus sucessos e fracassos e condições de operabilidade são de suma importância para a questão da regulação das corporações atuantes de maneira fluida (mas longe de ser soft) no cenário global.

Ademais, a própria complexificação dos processos normativos internos das ETNs - decorrentes, muitas vezes, dos próprios processos sociais reflexivos (pressão da sociedade sobre tais empresas; atuação empresarial negocial) - se especializa e impõe não só economicamente, mas também juridicamente, suas normas internas de conduta a setores reticulares inteiros bastante amplos. Nesse sentido, desconsiderar a importância da autorregulação de suas condutas como repletas de conteúdo normativo jurídico é postura teórica totalmente alheia em relação ao ambiente social em que o Direito se encontra. Em outras palavras: negar o pluralismo jurídico é negar a própria reflexividade entre Direito e sociedade.

Em síntese, pode-se considerar que a questão da regulação das ETNs se insere num âmbito complexo e pouco explorado, em que comunicações normativas 
multifatoriais reflexivas entre Estado, organizações internacionais e os próprios entes econômicos privados globais a serem regulados (muitas vezes por eles próprios) devem ser estabelecidas e analisadas. Trata-se de elevar qualitativamente a análise do fenômeno jurídico em sociedade no nível de complexidade que os processos sociais atuais exigem.

O referido âmbito complexo se relaciona às múltiplas possibilidades de regulação de suas condutas: não mais se pode observar no ordenamento estatal a única possibilidade de regê-las, eis que o nível de organização das ETNs supera os limites em que este é soberano; ademais, a regulação mediante postulados estabelecidos em ordens jurídicas internacionais, apesar da importância que podem assumir, não é o único complemento pensável à regulação estatal; e, por fim, tem-se que teorias jurídicas positivistas, em tempos de globalização e crise de soberania, não são capazes de abranger satisfatoriamente o fenômeno da emergência de um Direito plural que transborde a ideia de ordem estatal.

Por fim, âmbito ainda pouco explorado justamente em razão de tão arraigada cultura jurídica positivista tão cara à Modernidade. Essa cultura, exageradamente centrada na figura do Estado, abre pouca margem para uma observação plural de origem do fenômeno jurídico. Daí a necessidade de se buscar novos temas de pesquisa relacionados ao pluralismo jurídico, eis que o Estado, figura ainda importante para o Direito, não pode mais ser tido como único e absoluto centro emissor de normatividade na atualidade globalizada.

\section{REFERÊNCIAS}

ADEYEYE, Adefolake. Corporate responsibility in international law: which way to go? Singapore Yearbook of International Law, Singapore, v. 11, p. 141-161, 2007.

ALVAREZ, Jose E. Are corporations "subjects" of international law? Santa Clara Journal of International Law, Santa Clara, v. 9, n. 1, p. 01-36, 2011.

ANDERSON, Sarah; CAVANAGH, John. Top 200: the rise of corporate global power. Washington, D. C., 2000. Disponível em: <www.corpwatch.org/downloads/top200.pdf>. Acesso em: 22 jan. 2013.

BAUMAN, Zygmunt. Vidas desperdiçadas. Tradução de Carlos Alberto Medeiros. Rio de Janeiro: J. Zahar, 2005.
BROWNLIE, Ian. Princípios de direito internacional público. Lisboa: Fundação Calouste Gulbenkian, 1997.

CHINKIN, C. M. The challenge of soft law: development and change in international law. International and Comparative Law Quarterly, Cambridge, v. 38, p. 850-866, 1989.

DELEUZE, Gilles. Post-scriptum sobre as sociedades de controle. In: . Conversações. Trad. Peter Pál Pelbart. São Paulo: Editora 34, 2007. p. 219-226.

DEVA, Surya. Regulating corporate human rights violations: humanizing business. New York: Routledge, 2012.

EHRLICH, Eugen. Fundamentos da sociologia do direito. Brasília: UnB, 1986.

EINHORN, Aaron. The evolution and endpoint of responsibility: the FCPA, SOX, socialist-oriented governments, gratuitous promises, and a novel CSR code. Denver Journal of International Law and Policy, Denver, v. 35, p. 509-545, 2007.

FARIA, José Ângelo Estrella. A aplicação extraterritorial do direito da concorrência. Revista de Informação Legislativa, Brasília, v. 27, n. 105, p. 19-46, 1990.

FOUCAULT, Michel. Soberania e disciplina. In: - Microfísica do poder. Org. e trad. Roberto Machado. 20. ed. São Paulo: Graal, 2004. p. 100-107.

GÜNTHER, Gotthard. Life as poly-contexturality. fev. 2004. Disponível em: <http://www.vordenker.de/ ggphilosophy/gg_life_as_polycontexturality.pdf > . Acesso em: 13 abr. 2015.

GUZMAN, Andrew. Why LDCs sign treaties that hurt them? Virginia Journal of International Law, Charlottesville, v. 38, p. 640-688, 1998.

KAMMINGA, Menno T.; ZIA-ZARIF, Saman. Introduction. In: (Org.). Liability of multinational corporations under international law. Haia: Kluwer Law International, 2000. p. 01-16.

KELLER, Helen. Codes of conduct and their implementation: the question of legitimacy. In: WOLFRUM, Rüdger; VOLKER, Röben (Org.). Legitimacy in international law. Berlin: Springer, 2008. p. 219-298.

KELSEN, Hans. Derecho y paz en las relaciones internacionales. 2. ed. Mexico: Fondo de Cultura Económica, 1986.

KELSEN, Hans. Princípios do direito internacional. Ijuí: Unijuí, 2010. 
KINGSBURY, Benedict. The concept of compliance as a function of competing conceptions of international law. Michigan Journal of International Law, Ann Arbor, v. 19, p. 345-372, 1998.

LUHMANN, Niklas. Como se pueden observar estructuras latentes? In: WATZLAWICK, Pal; KRIEG, Peter. El ojo del observador: contribuciones al construtivismo. Barcelona: Gedisa, 1995. p. 60-72.

LUHMANN, Niklas. La ciencia de la sociedad. Tradução de Silvia Pappe, Brunhilde Erker e Luis Felipe Segura, sob a coordenação de Javier Torres Nafarrate. México: Universidad Iberoamericana, 1996.

LUHMANN, Niklas. Law as a social system. Tradução para o inglês de Klaus A. Ziegert. Oxford: Oxford University Press, 2004.

MACEDO, Stephen. The princeton principles on universal jurisdiction. Princeton: Princeton, 2001.

MALANCZUK, Peter. Akehurst's modern introduction to international law. 7. ed. New York: Routledge, 1997.

MUCHLINSKI, Peter T. Multinational enterprises and the law. 2. ed. Oxford: Oxford University Press, 2007.

MURPHY, Sean D. Taking multinational corporate codes of conduct to the next level. Columbia Transnational Law, New York, v. 43, p. 01-55, 2005.

NASSER, Salem Hikmat. Fontes e normas do direito internacional: um estudo sobre a soft law. 2. ed. São Paulo: Atlas, 2006.

NEVES, Marcelo. Transconstitucionalismo. São Paulo: M. Fontes, 2009.

NICHOLS, Philip M. The myth of anti-bribery laws as transnational intrusion. Cornell International Law Journal, Ithaca, v. 33, p. 627-655, 2000.

PECEQUILO, Cristina Soreanu. Introdução às relações internacionais. Petrópolis: Vozes, 2012.

PIETH, Mark. Article 4: jurisdiction. In: PIETH, Mark; LOW, Lucinda A.; CULLEN, Peter J (Org.). The OECD convention on bribery: a commentary. Cambridge: Cambridge University Press, 2007. p. 267-288.

ROBÉ, Jean-Philippe. Multinational enterprises: the constitution of a pluralistic legal order. In: TEUBNER, Gunther (Org.). Global law without a state. Vermont: Dartmouth, 1997. p. 45-77.

ROBINSON, Mary. Foreword. In: MACEDO, Stephen
(Org.). The Princeton principles on universal jurisdiction. Princeton: Princeton, 2001. p. 15-18.

ROCHA, Leonel Severo. A produção autopoética do sentido do direito. Direitos Culturais, Santo Ângelo, v. 4, n. 7, p. 13-26, 2009.

ROCHA, Leonel Severo. Epistemologia jurídica e democracia. 2. ed. São Leopoldo: Unisinos, 2003.

ROCHA, Leonel Severo; ATZ, Ana Paula. Do pluralismo jurídico ao diálogo inter-sistêmico das fontes na sociedade mundial. In: PEREIRA, Agostinho Oli Koppe; HORN, Luiz Fernando Del Rio (Org.). Relações de consumo: globalização. Caxias do Sul: Educs, 2010. p. 107-132.

SANTOS, Boaventura de Sousa. A crítica da razão indolente: contra o desperdício da experiência. São Paulo: Cortez, 2000.

SANTOS, Boaventura de Sousa. Notas sobre a história jurídico-social de Pasárgada. In: SOUZA JUNIOR, José Geraldo (Org.). O direito achado na rua. Brasília: UnB, 1987. p. 45-51.

SHAW, Malcolm N. Direito internacional. São Paulo: M. Fontes, 2010.

SHELTON, Dinah. International law and 'relative normativity'. In: EVANS, Malcolm (Org.). International law. 2. ed. Oxford: Oxford University Press, 2006. p. 159184.

SORNARAJAH, M. The international law of foreign investment. Cambridge: Cambridge University Press, 2010.

TEUBNER, Gunther. A bukowina global sobre a emergência de um pluralismo jurídico transnacional. Impulso, Piracicaba, v. 13, n. 33, p. 09-31, 2003.

TEUBNER, Gunther. Autoconstitucionalização de corporações transnacionais? sobre a conexão entre os códigos de conduta corporativos (Corporate Codes of Conduct) privados e estatais. In: SCHWARTZ, Germano (Org.). Juridicização das esferas e fragmentação do direito na sociedade contemporânea. Porto Alegre: Livraria do Advogado, 2012. p. 109-126.

TEUBNER, Gunther. After privatization? the many autonomies of private law. Current Legal Problems, London, v. 51, n. 1, p. 393-424, 2012.

WEIL, Prosper. Towards relative normativity in international law? The American Journal of International Law, Washington, v. 77, n. 3, p. 413-442, 1983. 
WELSCH, Wolfgang. Reason and transition: on the concept of transversal reason. 29 out. 2000. Disponível em: $\quad<$ http://ecommons.library.cornell.edu/bitstream/1813/54/1/Welsch_Reason_and_Transition. htm>. Acesso em: 13 abr. 2015.

WILKE, Helmut. Reflexivo (direito). In: ARNAUD, André-Jean (Dir.). Dicionário enciclopédico de teoria e de sociologia do direito. Rio de Janeiro: Renovar, 1999. p. 678-681.
WILKINS, Mira. European and north american multinationals, 1870-1914: comparions and contrasts. In: JONES, Geoffrey (Org.). Transnational corporations: a historical perspective. London: Routledge, 1992. p. 23-62. WOLKMER, Antonio Carlos. Pluralismo jurídico: fundamentos de uma nova cultura no direito. 3. ed. São Paulo: Alfa Omega, 2001. 
Para publicar na Revista de Direito Internacional, acesse o endereço eletrônico www.rdi.uniceub.br ou www.brazilianjournal.org.

Observe as normas de publicação, para facilitar e agilizar o trabalho de edição. 